\title{
Chemical Composition and Seasonality of Aromatic Mediterranean Plant Species by NMR-Based Metabolomics
}

\author{
Monica Scognamiglio, Brigida D’Abrosca, Assunta Esposito, and Antonio Fiorentino \\ Department of Environmental Biological and Pharmaceutical Sciences and Technologies, Second University of Naples, \\ Via Vivaldi 43, 81100 Caserta, Italy \\ Correspondence should be addressed to Monica Scognamiglio; monica.scognamiglio@unina2.it
}

Received 17 November 2014; Revised 28 January 2015; Accepted 30 January 2015

Academic Editor: Gowda A. Nagana Gowda

Copyright (C) 2015 Monica Scognamiglio et al. This is an open access article distributed under the Creative Commons Attribution License, which permits unrestricted use, distribution, and reproduction in any medium, provided the original work is properly cited.

\begin{abstract}
An NMR-based metabolomic approach has been applied to analyse seven aromatic Mediterranean plant species used in traditional cuisine. Based on the ethnobotanical use of these plants, the approach has been employed in order to study the metabolic changes during different seasons. Primary and secondary metabolites have been detected and quantified. Flavonoids (apigenin, quercetin, and kaempferol derivatives) and phenylpropanoid derivatives (e.g., chlorogenic and rosmarinic acid) are the main identified polyphenols. The richness in these metabolites could explain the biological properties ascribed to these plant species.
\end{abstract}

\section{Introduction}

Aromatic plants are widespread throughout the world and they are extensively added to different food preparations. The use of these plants is very popular and has a long tradition in Mediterranean area [1].

Plants in general have been shown to produce a wide range of chemicals, traditionally categorized into primary and secondary metabolites. For the sake of simplicity, primary metabolites can be thought of to serve nutritional purposes, while secondary metabolites are required by plants as weapons against competitors, herbivores or pathogens, and so forth [2]. However, both classes of metabolites are important for the plant itself but also for their actions on plant consumers and mainly in case of edible plants.

Many aromatic plants are added to foods and eaten. The whole plants or one or some of their components are used as, for example, food preservatives, flavour, and additives. Nevertheless, it has been shown that chemical composition of plants is highly variable along the year. Several analytical techniques are available for studying plant metabolites' content. Most of them are targeted techniques as an a priori knowledge on the metabolites to be analysed is required [2,3]. Furthermore, for aromatic plants, a great effort has been devoted to the study of essential oils $[2,4]$.
Given this background, a wider knowledge about their whole metabolite content is needed. To this end, a very powerful approach is metabolomics, the comprehensive analysis of the set of low molecular weight compounds of a biological system under a given condition [5]. Analogously, other related approaches, like metabolic profiling [6], could be used.

In particular, NMR-based metabolomics has been shown to be very useful due to its untargeted and unbiased features [7]. Furthermore, it is highly reproducible, it allows the contemporary identification and quantification of a large number of compounds and needs short times of analysis (including the extraction procedures) [6]. The only limitation of NMR is its low sensitivity when compared to mass spectrometry, although sensitivity has been drastically increased with recent advances like higher magnetic fields and the introduction of microcryoprobes $[5,8]$. On the other hand, NMR allows the identification of unknown compounds in the analysed mixtures, as it gives important structural information [8].

In order to demonstrate the potentiality of this approach, it has been applied to seven aromatic plant species characteristic of Mediterranean garrigue: the metabolites' content of these plants has been determined and the seasonality of their accumulation has been studied. 
TABle 1: Studied plants.

\begin{tabular}{|c|c|c|}
\hline $\begin{array}{l}\text { Species and voucher } \\
\text { specimen }\end{array}$ & Family & Uses \\
\hline $\begin{array}{l}\text { Calamintha nepeta L. } \\
\text { CE236 }\end{array}$ & Lamiaceae & $\begin{array}{l}\text { Leaf used as food spice (usually added to meat, fish, and vegetable dishes; mint aroma) } \\
\text { and for medicinal purposes (antiseptic, tonic, antispasmodic, diaphoretic, expectorant, } \\
\text { etc.) }[25,26]\end{array}$ \\
\hline $\begin{array}{l}\text { Helichrysum italicum } \mathrm{G} . \\
\text { Don CE233 }\end{array}$ & Asteraceae & $\begin{array}{l}\text { Leaf used as food spice (also known as "curry plant") and for medicinal purposes } \\
\text { (anti-inflammatory and anti-infective, antiallergic, etc.) essential oils used in cosmetics } \\
{[16,27]}\end{array}$ \\
\hline $\begin{array}{l}\text { Foeniculum vulgare Mill. } \\
\text { CE237 }\end{array}$ & Apiaceae & $\begin{array}{l}\text { Leaf and fruits used to flavour several kinds of dishes. Also used in cosmetics and } \\
\text { pharmaceutical products [28] }\end{array}$ \\
\hline $\begin{array}{l}\text { Micromeria graeca L. } \\
\text { CE238 }\end{array}$ & Lamiaceae & Leaf used as food spice (added to meat and vegetables) \\
\hline Origanum vulgare L. CE239 & Lamiaceae & $\begin{array}{l}\text { Dried plant (epigeous part) used as food spice. The most common spice in } \\
\text { Mediterranean cuisine. Used, since ancient times, for medicinal purposes (antioxidant } \\
\text { digestive, expectorant, antiseptic, antispasmodic, etc.) [29] }\end{array}$ \\
\hline Satureja montana L. CE234 & Lamiaceae & $\begin{array}{l}\text { Leaf used as food spice (usually added to meat, fish, and vegetable dishes). Natural } \\
\text { food preservative. Savory honey is a very common ingredient in folk remedies. Used } \\
\text { for medicinal purposes [30] }\end{array}$ \\
\hline $\begin{array}{l}\text { Thymus longicaulis C. Presl } \\
\text { CE235 }\end{array}$ & Lamiaceae & $\begin{array}{l}\text { Leaf used as food spice (usually added to meat, fish, and vegetable dishes). Natural } \\
\text { food preservative. Used also for medicinal purposes [31] }\end{array}$ \\
\hline
\end{tabular}

\section{Materials and Methods}

2.1. Plant Material Sampling and Processing. Seven plant species (Table 1) were collected in a garrigue on the calcareous hills of Durazzano, $\left(41^{\circ} 3^{\prime} \mathrm{N}, 14^{\circ} 27^{\prime} \mathrm{E}\right.$; southern Italy) in winter (February 2012), spring (May 2012), summer (July 2012), and autumn (October 2012). The plants were selected based on their occurrence in the study site. Origanum vulgare samples were not available in autumn. Plant leaf samples were collected in the field always at the same moment of the day, in order to minimize differences due to metabolites changing based on circadian clock.

Three leaf samples (biological replicates) of each plant species were harvested and immediately frozen in liquid $\mathrm{N}_{2}$ in order to avoid unwanted enzymatic reactions and stored at $-80^{\circ} \mathrm{C}$ up to the freeze drying process. Once freeze dried they were powdered in liquid nitrogen and stored at $-20^{\circ} \mathrm{C}$. Each sample was extracted and analysed by NMR.

Voucher specimens for all the plant species were deposited at the herbarium of the Second University of Naples (Table 1).

2.2. Metabolomics Analysis. Freeze-dried plant material (50 mg) was transferred to a $2 \mathrm{~mL}$ microtube. NMR samples were prepared in a mixture of phosphate buffer (Fluka Chemika; $90 \mathrm{mM}$; $\mathrm{pH}$ 6.0) in $\mathrm{D}_{2} \mathrm{O}$ (Cambridge Isotope Laboratories) containing $0.1 \% \mathrm{w} / \mathrm{w}$ trimethylsilylpropionic$2,2,3,3-d_{4}$ acid sodium salt (TMSP, Sigma-Aldrich) and methanol- $d_{4}$ (Sigma-Aldrich). A volume of $1.5 \mathrm{~mL}$ of phosphate buffer and methanol- $d_{4}(1: 1)$ was added to the plant samples. The mixture was vortexed at room temperature for $1 \mathrm{~min}$, ultrasonicated (Elma Transonic Digitals) for $40 \mathrm{~min}$, and centrifuged (Beckman Allegra 64R) at $13000 \mathrm{rpm}$ for $10 \mathrm{~min}$. An aliquot of $0.6 \mathrm{~mL}$ was transferred to an NMR tube and analysed by NMR [9]. NMR spectra were recorded at $25^{\circ} \mathrm{C}$ on a $300.03 \mathrm{MHz}$ for ${ }^{1} \mathrm{H}$ and $75.45 \mathrm{MHz}$ for ${ }^{13} \mathrm{C}$ on a Varian Mercury Plus 300 Fourier transform NMR. $\mathrm{CD}_{3} \mathrm{OD}$ was used as the internal lock. Each ${ }^{1} \mathrm{H}$ NMR spectrum consisted of 256 scans with the following parameters: $0.16 \mathrm{~Hz} /$ point, acquisition time $(A Q)=1.0 \mathrm{~s}$, relaxation delay $(\mathrm{RD})=1.5 \mathrm{~s}$, $90^{\circ}$ pulse width $(\mathrm{PW})=13.8 \mu \mathrm{s}$. A presaturation sequence was used to suppress the residual $\mathrm{H}_{2} \mathrm{O}$ signal. Free induction decays (FIDs) were Fourier transformed with $\mathrm{LB}=0.3 \mathrm{~Hz}$ and the resulting spectra were manually phased and baselinecorrected and calibrated to TMSP at $0.0 \mathrm{ppm}$, using ${ }^{1} \mathrm{H}$ NMR processor (MestReNova, version 8.0.2).

2.3. Quantitative Analysis. The main metabolites identified in plant extracts were analyzed by quantitative analysis. ${ }^{1} \mathrm{H}$ NMR spectra were bucketed, reducing it to integral segments with a width of $0.02 \mathrm{ppm}$ with ACDLABS $12.0{ }^{1} \mathrm{H}-\mathrm{NMR}$ processor (ACDLABS 12.0, Toronto, Canada). Spectra were scaled to the internal standard (whose area, from -0.01 to $0.01 \mathrm{ppm}$, was set equal to 1 ). For each metabolite, buckets corresponding to nonoverlapping signals were used to calculate the relative amount as follows:

$$
\text { Metabolite relative amount }=\frac{\mathrm{SA} \times n_{\mathrm{HTMSP}}}{n_{\mathrm{S}}},
$$

where $\mathrm{SA}$ is the metabolite signal area, but it is also equal to the signal area/standard area ratio, as standard area is equal to $1 ; n_{\text {HTMSP }}$ is a constant equal to 9 (the number of protons responsible for the signal between -0.01 and $0.01 \mathrm{ppm}$ ) and $n_{s}$ is the number of protons of the metabolite signal area [10].

\section{Results and Discussion}

Recent research has shown culinary herbs and spices as a source of bioactive compounds [11]. Although most of them have been extensively studied for their essential oil 
composition, far less information is available on their polar and semipolar chemical composition.

Herewith, seven Mediterranean plants (Calamintha nepeta, Helichrysum italicum, Foeniculum vulgare, Micromeria graeca, Origanum vulgare, Satureja montana, and Thymus longicaulis) have been studied for their metabolite content by NMR. The identification of metabolites was carried out by comparing NMR data with an in-house library, with databases [12], and with some literature data [10, 13-15]. ${ }^{1} \mathrm{H}-\mathrm{NMR}$ data and extract composition are given in Table 2 and spectra are shown in Figure 1.

Primary metabolites were easily identified based on data extensively reported in literature of spectra acquired in the same solvent mixture [10, 12-15]. Among free amino acids, alanine was observed in all of the plants, while threonine was only detected in Micromeria graeca and Foeniculum vulgare.

The sugar content was highly variable, with glucose and sucrose as the main free carbohydrates detected.

Finally, some organic acids were identified. Quinic acid was present in all of the plants but Helichrysum italicum and Satureja montana, while malic acid was clearly detected in all of the plants.

Concerning the secondary metabolite content, the analysed Lamiaceae plants were all characterized by the presence of high amounts of rosmarinic acid (with the exception of C. nepeta), along with analogous compounds. Caffeic acid was identified based on comparison of NMR data with the literature $[10,15]$ and confirmed by comparison with NMR spectra of an in-house library. Rosmarinic acid was identified based on the comparison with already reported data [10] and the structure was confirmed by 2D NMR analysis. Indeed, the olefinic proton at $\delta 7.50(\mathrm{H} 7)$ (showing HSQC correlation with the carbon at $\delta$ 145.9) and that at $\delta 6.30$ (showing HSQC correlation with the carbon at $\delta 114.3$ ) showed long range correlations with a carbon at $\delta 168.4$ (C9). This carbon was in turn correlated with the proton at $\delta 5.02\left(\mathrm{H}^{\prime}\right)$, confirming the linkage between a caffeoyl moiety and the 3,4dihydroxyphenyl lactic acid moiety. Furthermore, the former was identified based on the long range correlation of the $\mathrm{H} 7$ olefinic proton with the aromatic carbon at $\delta 126.4(\mathrm{C} 1)$, showing further correlations with the signals belonging to an ortho/para trisubstituted aromatic ring (Table 2). The latter was identified as follows: the proton $\mathrm{H}^{\prime}$ showed correlations with a carboxylic carbon at $\delta 176.5$ and with a methylene carbon at $\delta 36.9\left(\mathrm{C7}^{\prime}\right)$, showing HSQC correlations with the diastereotopic protons $\mathrm{H}^{\prime}$ (Table 2). The proton $\mathrm{H}^{\prime}$ also showed long range correlation with a quaternary aromatic carbon at $\delta 130.0\left(\mathrm{Cl}^{\prime}\right)$, in turn correlated with the signals belonging to a second ortho/para trisubstituted aromatic ring (Table 2).

Some phenylpropanoids in the extracts were not definitively characterized, inasmuch as, based on their scarce abundance and/or strong signal overlapping, they did not show clear correlations in 2D NMR spectra. However, the characteristic signals and correlations of the trans-propenylic chain suggested their presence. Indeed, correlations were observed in the HSQC, among the olefinic signals with carbons at 140-145 ppm (for the proton at lower fields) and at 114-120 ppm (for the proton at higher fields) and long range correlations were shown with carbon resonances attributable to ester carboxyl carbons and with quaternary aromatic carbons.

Calamintha nepeta extracts were also rich in several flavonoids and phenylpropanoids. Unfortunately, it was not possible to definitely characterize these compounds, but all of the flavonoids were identified as apigenin derivatives (Table 2). Indeed, several sets of resonances attributable to meta coupled protons $\mathrm{H} 7 / \mathrm{H} 8$ ( ring A), to proton $\mathrm{H} 3$ and to $\mathrm{B}$ ring ortho coupled protons were detected. Interestingly, the compounds, probably characterized by a different degree of glycosylation, showed a peculiar distribution along the seasons. Two apigenin derivatives were detected in spring and autumn (apigenin derivatives 1 and 2), while two different couples of these compounds were detected in summer (apigenin derivatives 3 and 4) and winter (apigenin derivatives 5 and 6) samples. Moreover, apigenin derivatives 5 and 6 were detected only in winter also in Satureja montana.

Analogously, as shown in Table 2, the presence of some phenylpropanoids was strongly dependent on the collection season (Table 2): phenylpropanoid 2 was detected only in winter, phenylpropanoid 5 only in spring, phenylpropanoid 6 only in summer, and phenylpropanoid 7 only in autumn samples.

The most stable metabolome along the seasons was detected for Thymus longicaulis while Micromeria graeca and Origanum vulgare only changed for some metabolites. However, differences in the amounts of the compounds were observed. Indeed, for all the Lamiaceae plants, a higher amount of aromatic compounds (Table 2) was observed in spring and summer samples compared to autumn and winter samples. Helichrysum italicum and Foeniculum vulgare extracts showed an analogous behaviour, with changes of metabolites mainly on the quantitative point of view.

Helichrysum italicum extracts, besides chlorogenic acids, also showed signals attributable to a 3-hydroxybenzofuran and an isobenzofuranone derivative. Chlorogenic, neochlorogenic, and dicaffeoylquinic acids were identified based on comparison of ${ }^{1} \mathrm{H}-\mathrm{NMR}$ data with the literature $[10$, 15] and with the in-house library. The caffeoyl moiety was clearly identified based on $1 \mathrm{D}$ and 2D NMR data and the linkage(s) with the quinic acid moiety was confirmed by the correlation observed in the long range spectrum. The $3-$ hydroxybenzofuran and isobenzofuranone derivatives were identified based on comparison with the NMR spectrum of the compound previously isolated [16].

Finally, Foeniculum vulgare was characterized by chlorogenic acids and flavonoids, identified, based on ${ }^{1} \mathrm{H}-\mathrm{NMR}$ data as kaempferol and quercetin [17]. Chlorogenic acid was reported for the first time from this species, to the best of our knowledge.

The identification of water soluble compounds in these plants is very important as most of them are added to dishes; hence they might be eaten or however they could release bioactive compounds into food. In this framework, it is worth to underlining that first of all the health promoting capacity of bioactive compounds could be dependent on synergisms. Secondly, these plants could also contain potential toxic 


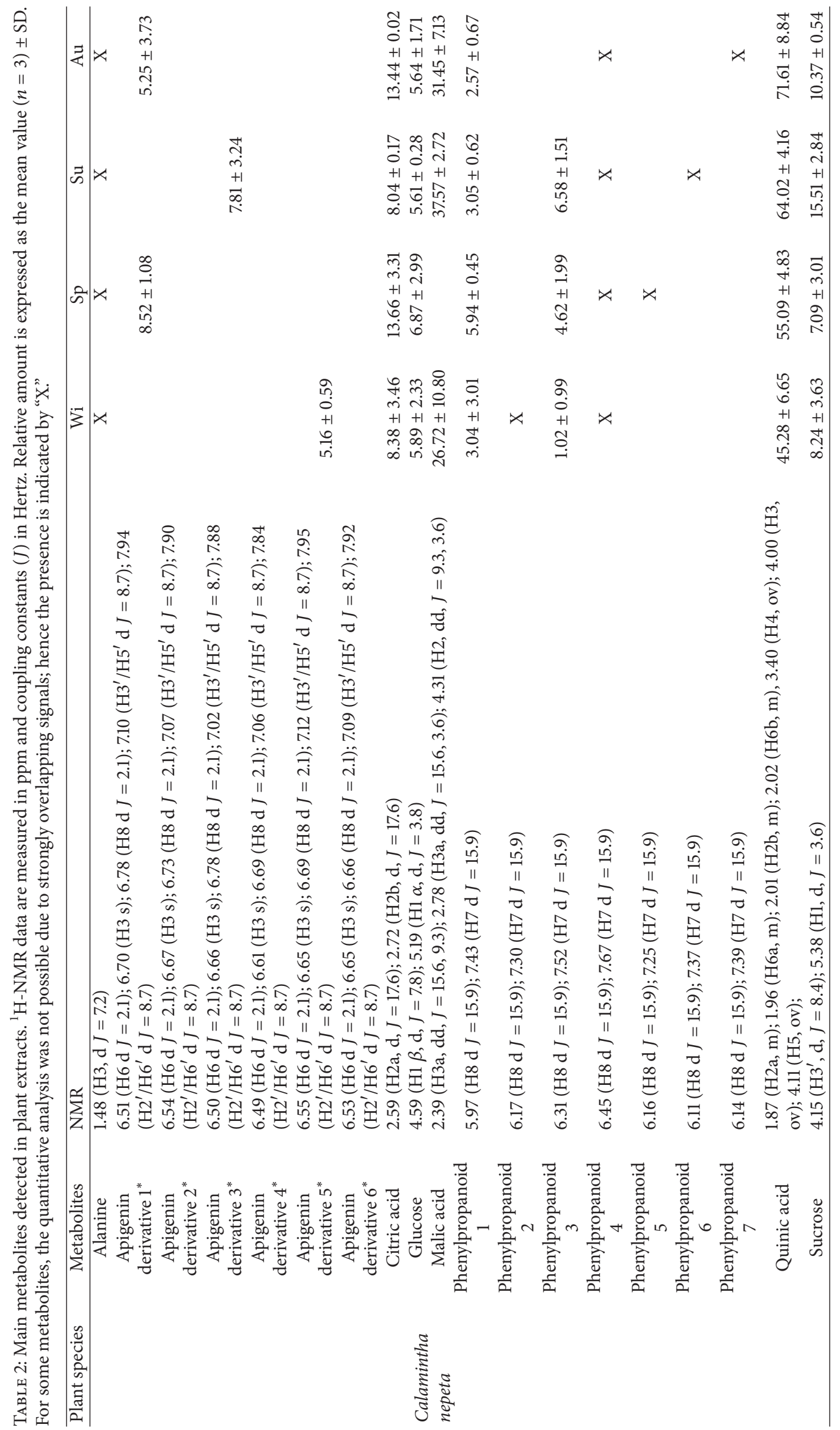




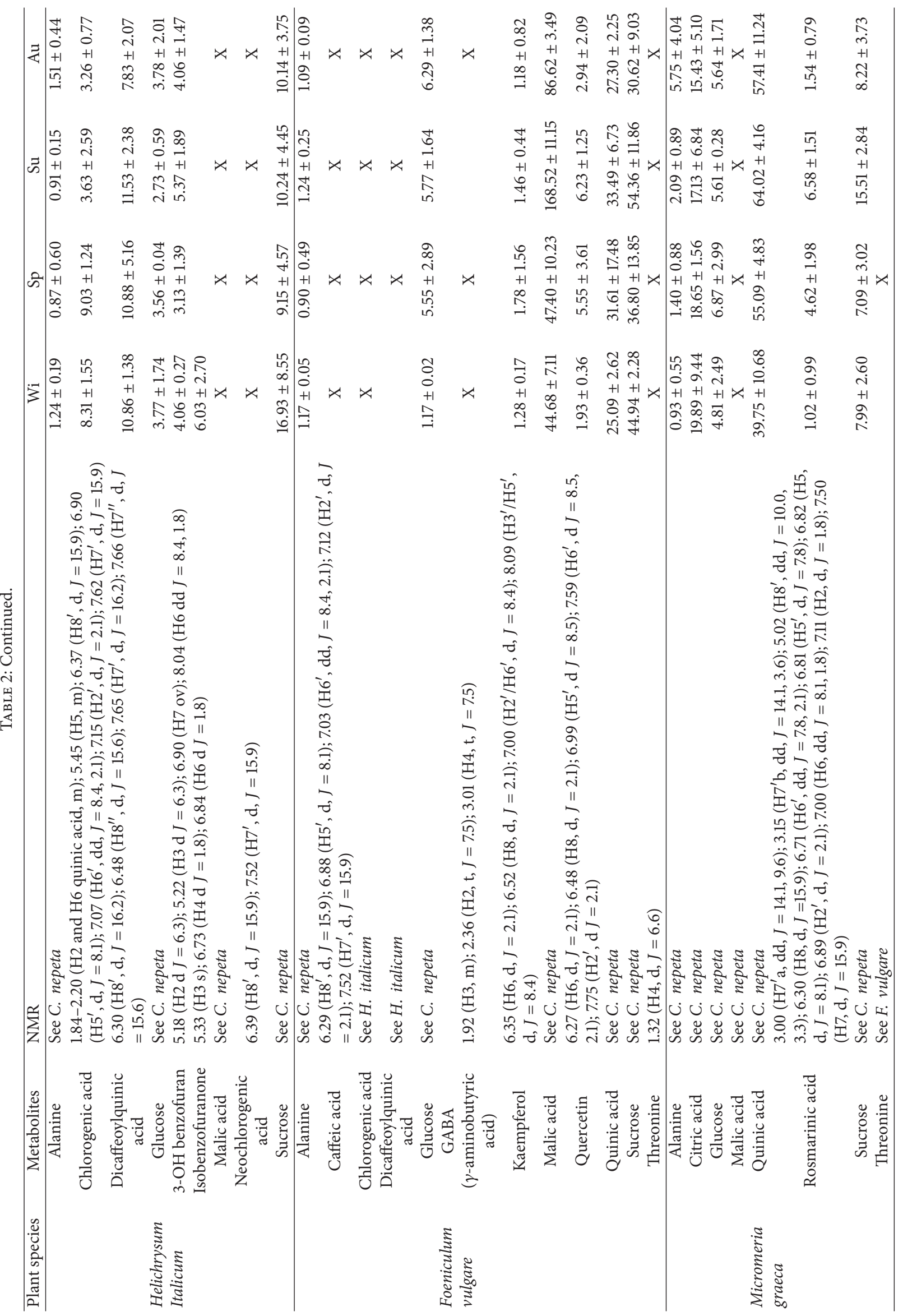




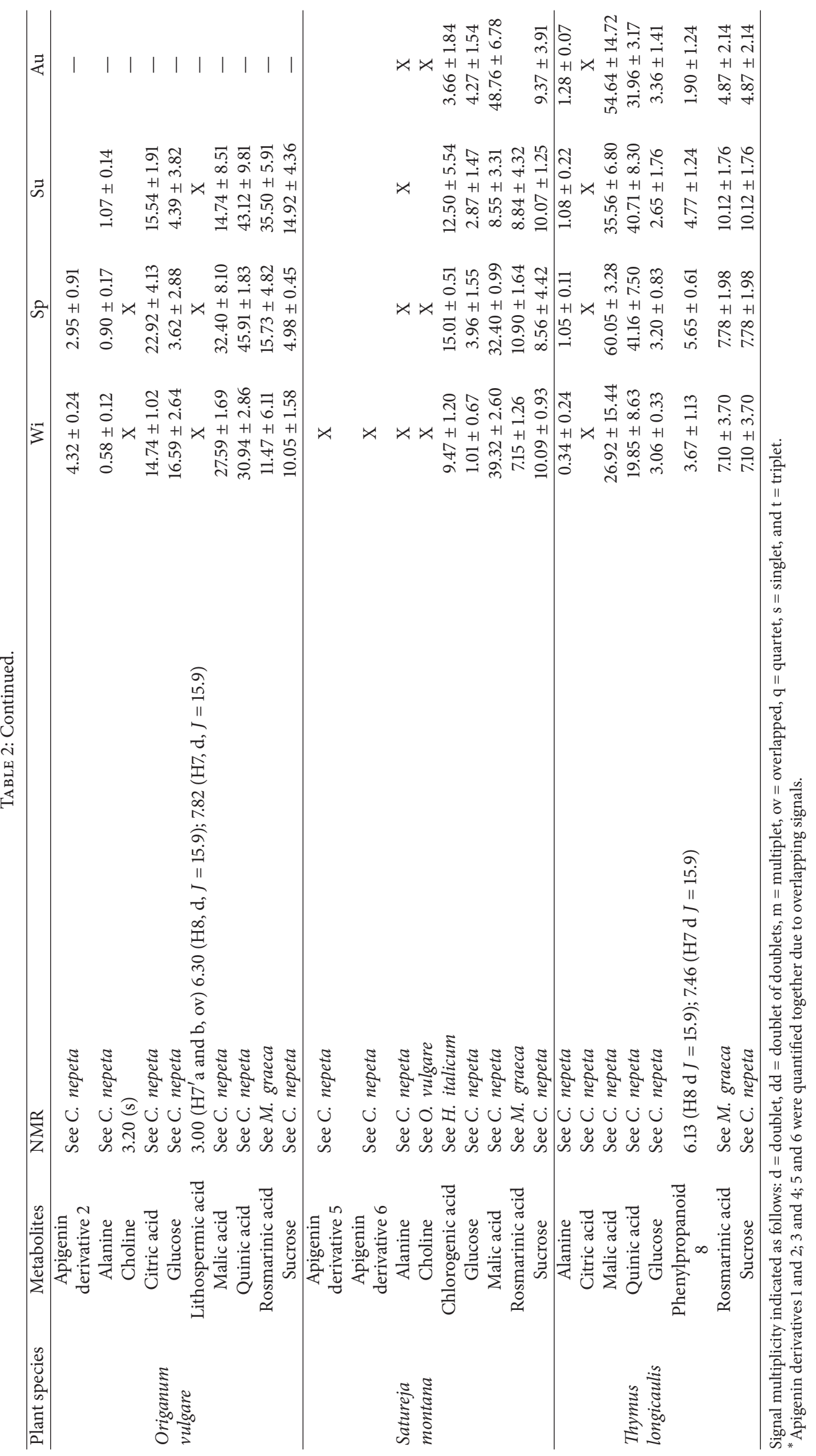



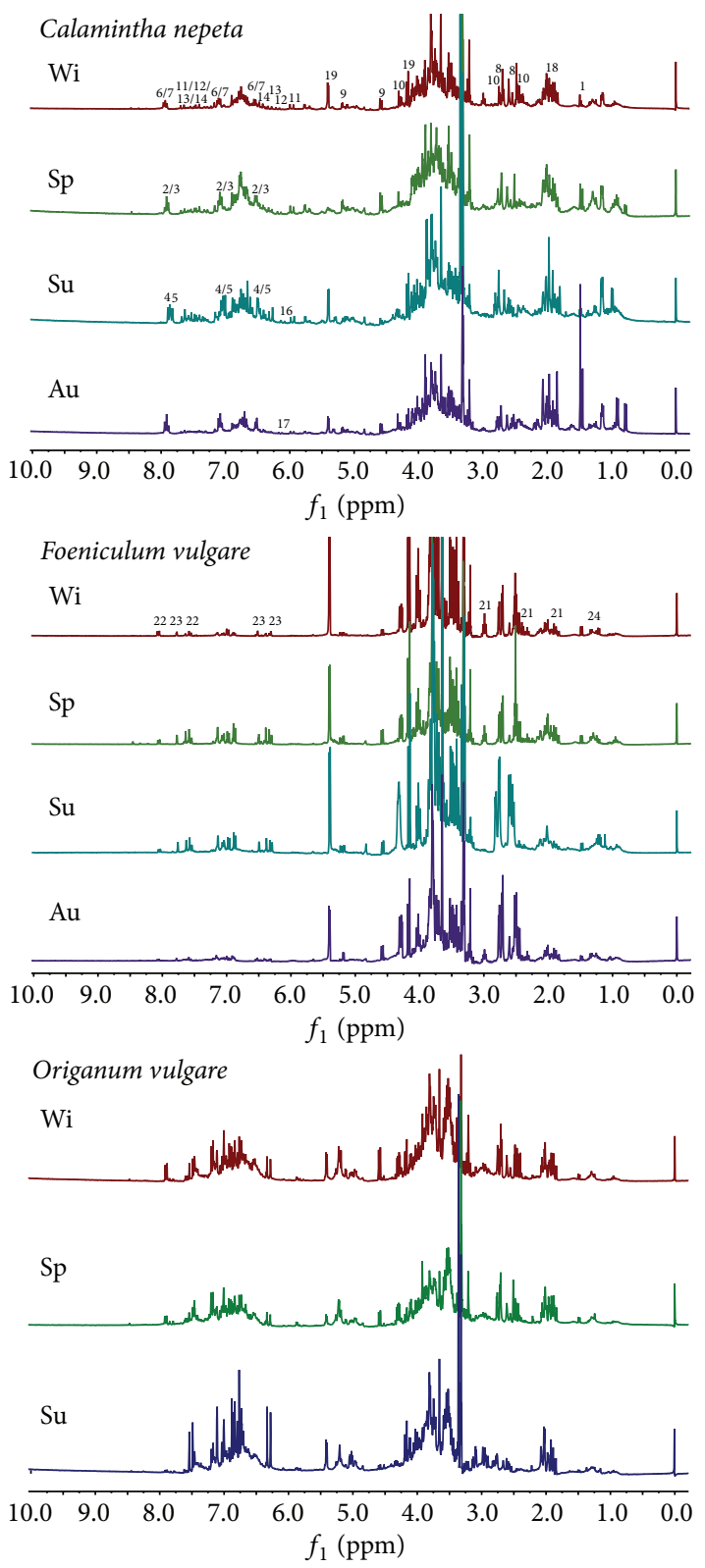

Thymus longicaulis

$\mathrm{Wi}$

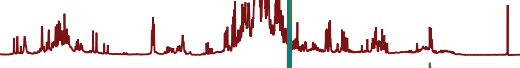

Sp<smiles>c1cn2c3cnc2c1n3</smiles>

$\mathrm{Su}$

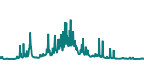

$\begin{array}{lllllll}0.0 & 9.0 & 8.0 & 7.0 & 6.0 & \begin{array}{c}5.0 \\ f_{1}(\mathrm{ppm})\end{array}\end{array}$

Satureja montana

$\mathrm{Wi}$

Micromeria graeca

$\mathrm{W}$

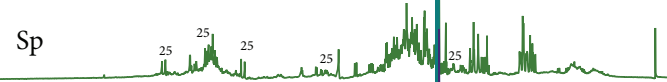

$\mathrm{Su}$

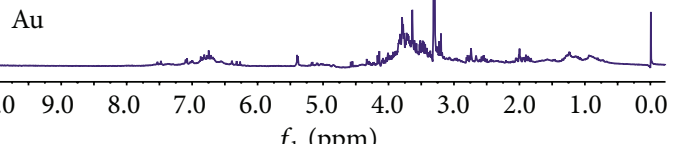

$\mathrm{Sp}$

$\mathrm{Au}$

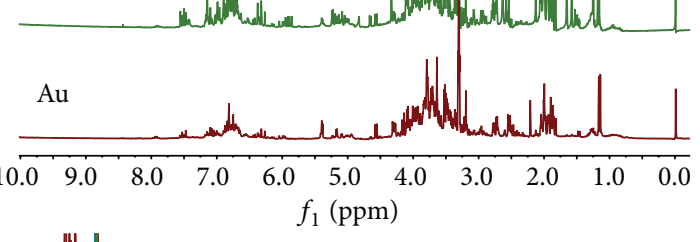

Helichrysum italicum

$\mathrm{Au}$

5.0
$f_{1}(\mathrm{ppm})$$$
\text { (1.0.0.0. }
$$
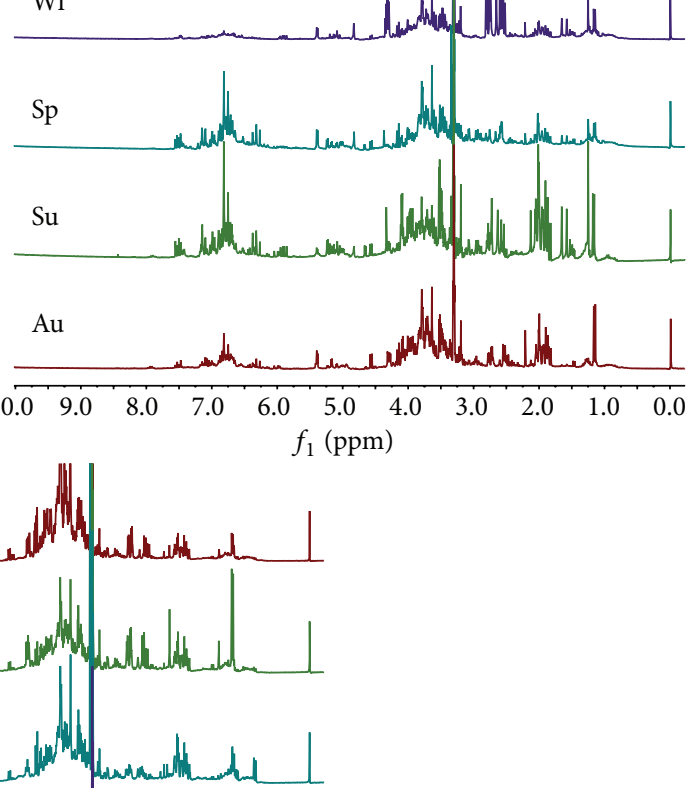

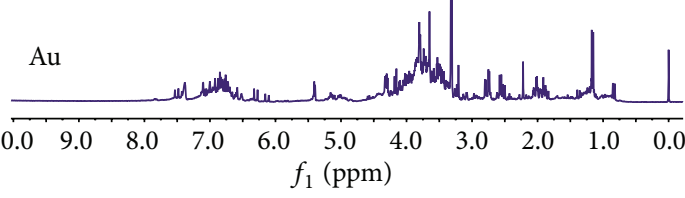

FiguRE 1: ${ }^{1} \mathrm{H}$-NMR spectra of studied plants $(\mathrm{Au}=$ autumn; $\mathrm{Sp}=$ spring; $\mathrm{Su}=$ summer; $\mathrm{Wi}=$ winter). The main resonances of the main compounds are indicated on the spectra as follows: 1 , alanine; 2 , apigenin derivative $1 ; 3$, apigenin derivative $2 ; 4$, apigenin derivative $3 ; 5$, apigenin derivative $4 ; 6$, apigenin derivative $5 ; 7$, apigenin derivative $6 ; 8$, citric acid; 9 , glucose; 10 , malic acid; 11, phenylpropanoid 1; 12, phenylpropanoid 2; 13, phenylpropanoid 3; 14, phenylpropanoid 4; 15, phenylpropanoid 5; 16, phenylpropanoid 6; 17, phenylpropanoid 7; 18, quinic acid; 19, sucrose; 20, chlorogenic acid; 21, GABA; 22, kaempferol; 23, quercetin; 24, threonine; 25, rosmarinic acid. 
compounds, as reported for several Lamiaceae [17]. Nevertheless, the role in nutrition of primary metabolites is often disregarded [18]. These considerations raise the attention to the need for a comprehensive profiling of their metabolites.

Furthermore, the NMR-based metabolomic approach here proposed, due to the short time of analyses and to lower costs compared to other analytical methods, was very useful for the study of seasonal variation of metabolites.

Indeed, although it is clear that secondary metabolites show peculiar trends, only fragmentary information is available, mainly because of the used approaches.

The most common and easiest procedure was to perform the phytochemical study on samples collected in a specific time of the year and then compare the other months (or seasons) by setting up a series of target analyses, often by HPLC $[19,20]$ or by less time and resource consuming approaches based on colorimetric assays [21].

The improvement of analytical methods, and especially the availability of a high-throughput approach like metabolomics [5], gives the chance to further explore the issue of seasonality [22] and to thoroughly study these changes.

Concerning the metabolites identified within the extracts, it is important to underline their biological activity.

Phenols are well known for their antioxidant activity [11]. As the studied plants are all very rich in phenolics, they have a great antioxidant potential. This could also explain the use of some of these herbs as natural food preservatives (Table 1).

Among the detected compounds, rosmarinic acid is the most widespread and the most abundant. A plethora of biological activities has been attributed to this compound, among them: adstringent, antioxidative, anti-inflammatory, antimutagen, antibacterial, and antiviral [23].

Many other phenylpropanoids and flavonoids were also detected. Several properties have been reported for these compounds, such as anti-inflammatory, antimicrobial, and antitumor activity [24].

The richness in these compounds of the studied plants supports their traditional uses.

However, the study evidenced that qualitative and quantitative variations of metabolites are observed along the year.

This is, to the best of our knowledge, the first report of metabolite content and seasonal qualitative and quantitative variation of this set of food spices. Furthermore, it is evidenced that a higher content of compounds known for their health promoting capacities can be found in spring and summer samples of all the analysed species, although seasonspecific compounds were also detected.

\section{Conclusions}

NMR-based metabolomics has been applied to the study of chemical composition of selected aromatic plants of Mediterranean vegetation.

The method allowed determining the chemical composition of plant extracts in terms of primary and secondary metabolites. The abundance of aromatic secondary metabolites suggested that the traditional uses of these plants might be supported by their chemical composition.
Furthermore, the seasonality of the accumulation of these metabolites was studied.

\section{Conflict of Interests}

The authors declare that there is no conflict of interests regarding the publication of this paper.

\section{Acknowledgment}

The authors would like to thank the anonymous reviewers for their valuable suggestions.

\section{References}

[1] A. M. Scherrer, R. Motti, and C. S. Weckerle, "Traditional plant use in the areas of Monte Vesole and Ascea, Cilento National Park (Campania, Southern Italy)," Journal of Ethnopharmacology, vol. 97, no. 1, pp. 129-143, 2005.

[2] T. Efferth and H. J. Greten, "Medicinal and aromatic plant research in the 21st century," Medicinal \& Aromatic Plants, vol. 1, article e110, 2012.

[3] R. Rodríguez-Solana, J. M. Salgado, J. M. Domínguez, and S. Cortés-Diéguez, "Comparison of soxhlet, accelerated solvent and supercritical fluid extraction techniques for volatile (GC-MS and GC/FID) and phenolic compounds (HPLCESI/MS/MS) from Lamiaceae Species ," Phytochemical Analysis, vol. 26, no. 1, pp. 61-71, 2015.

[4] T. Fornari, G. Vicente, E. Vázquez, M. R. García-Risco, and G. Reglero, "Isolation of essential oil from different plants and herbs by supercritical fluid extraction," Journal of Chromatography A, vol. 1250, pp. 34-48, 2012.

[5] H. K. Kim, Y. H. Choi, and R. Verpoorte, "NMR-based plant metabolomics: where do we stand, where do we go?" Trends in Biotechnology, vol. 29, no. 6, pp. 267-275, 2011.

[6] M. Scognamiglio, B. D’Abrosca, A. Esposito, and A. Fiorentino, "Metabolomics: an unexplored tool for allelopathy studies," Journal of Allelochemical Interactions, vol. 1, pp. 9-23, 2015.

[7] J. W. Allwood, D. I. Ellis, and R. Goodacre, "Metabolomic technologies and their application to the study of plants and plant-host interactions," Physiologia Plantarum, vol. 132, no. 2, pp. 117-135, 2008.

[8] R. R. Forseth and F. C. Schroeder, "NMR-spectroscopic analysis of mixtures: from structure to function," Current Opinion in Chemical Biology, vol. 15, no. 1, pp. 38-47, 2011.

[9] H. K. Kim, Y. H. Choi, and R. Verpoorte, "NMR-based metabolomic analysis of plants," Nature Protocols, vol. 5, no. 3, pp. 536-549, 2010.

[10] M. Scognamiglio, V. Fiumano, B. DAbrosca et al., "Chemical interactions between plants in Mediterranean vegetation: the influence of selected plant extracts on Aegilops geniculata metabolome," Phytochemistry, vol. 106, pp. 69-85, 2014.

[11] A. Vallverdú-Queralt, J. Regueiro, M. Martínez-Huélamo, J. F. R. Alvarenga, L. N. Leal, and R. M. Lamuela-Raventos, "A comprehensive study on the phenolic profile of widely used culinary herbs and spices: rosemary, thyme, oregano, cinnamon, cumin and bay," Food Chemistry, vol. 154, pp. 299307, 2014.

[12] Q. Cui, I. A. Lewis, A. D. Hegeman et al., "Metabolite identification via the Madison Metabolomics Consortium Database," Nature Biotechnology, vol. 26, no. 2, pp. 162-164, 2008. 
[13] A. Lubbe, H. Gude, R. Verpoorte, and Y. H. Choi, "Seasonal accumulation of major alkaloids in organs of pharmaceutical crop Narcissus Carlton," Phytochemistry, vol. 88, pp. 43-53, 2013.

[14] R. Verpoorte, Y. H. Choi, and H. K. Kim, "NMR-based metabolomics at work in phytochemistry," Phytochemistry Reviews, vol. 6, no. 1, pp. 3-14, 2007.

[15] J.-L. Wolfender, S. Rudaz, Y. H. Choi, and H. K. Kim, "Plant metabolomics: from holistic data to relevant biomarkers," Current Medicinal Chemistry, vol. 20, no. 8, pp. 1056-1090, 2013.

[16] B. D’Abrosca, E. Buommino, G. D’Angelo et al., "Spectroscopic identification and anti-biofilm properties of polar metabolites from the medicinal plant Helichrysum italicum against Pseudomonas aeruginosa," Bioorganic and Medicinal Chemistry, vol. 21, no. 22, pp. 7038-7046, 2013.

[17] S. Pacifico, B. D’Abrosca, M. Scognamiglio et al., "NMR-based metabolic profiling and in vitro antioxidant and hepatotoxic assessment of partially purified fractions from Golden germander (Teucrium polium L.) methanolic extract," Food Chemistry, vol. 135, no. 3, pp. 1957-1967, 2012.

[18] R. Scherer, A. C. P. Rybka, C. A. Ballus, A. D. Meinhart, J. T. Filho, and H. T. Godoy, "Validation of a HPLC method for simultaneous determination of main organic acids in fruits and juices," Food Chemistry, vol. 135, no. 1, pp. 150-154, 2012.

[19] J. Liimatainen, M. Karonen, J. Sinkkonen, M. Helander, and J.-P. Salminen, "Phenolic compounds of the inner bark of Betula pendula: seasonal and genetic variation and induction by wounding," Journal of Chemical Ecology, vol. 38, no. 11, pp. 1410-1418, 2012.

[20] K. Hosni, K. Msaada, M. Ben Taârit, and B. Marzouk, "Phenological variations of secondary metabolites from Hypericum triquetrifolium Turra," Biochemical Systematics and Ecology, vol. 39, no. 1, pp. 43-50, 2011.

[21] F. Brahmi, B. Mechri, S. Dabbou, M. Dhibi, and M. Hammami, "The efficacy of phenolics compounds with different polarities as antioxidants from olive leaves depending on seasonal variations," Industrial Crops and Products, vol. 38, no. 1, pp. 146-152, 2012.

[22] A. Lubbe, H. Gude, R. Verpoorte, and Y. H. Choi, "Seasonal accumulation of major alkaloids in organs of pharmaceutical crop Narcissus Carlton," Phytochemistry, vol. 88, pp. 43-53, 2013.

[23] M. Petersen and M. S. J. Simmonds, "Rosmarinic acid," Phytochemistry, vol. 62, no. 2, pp. 121-125, 2003.

[24] R. Quirantes-Piné, M. Herranz-López, L. Funes et al., "Phenylpropanoids and their metabolites are the major compounds responsible for blood-cell protection against oxidative stress after administration of Lippia citriodora in rats," Phytomedicine, vol. 20, no. 12, pp. 1112-1118, 2013.

[25] G. Tibaldi, E. Fontana, and S. Nicola, "Postharvest management affects spearmint and calamint essential oils," Journal of the Science of Food and Agriculture, vol. 93, no. 3, pp. 580-586, 2013.

[26] K. Hammer, G. Laghetti, and K. Pistrick, "Calamintha nepeta (L.) Savi and Micromeria thymifolia (Scop.) Fritsch cultivated in Italy," Genetic Resources and Crop Evolution, vol. 52, no. 2, pp. 215-220, 2005.

[27] G. Appendino, M. Ottino, N. Marquez et al., "Arzanol, an antiinflammatory and anti-HIV-1 phloroglucinol $\alpha$-pyrone from Helichrysum italicum ssp. microphyllum," Journal of Natural Products, vol. 70, no. 4, pp. 608-612, 2007.

[28] W.-R. Diao, Q.-P. Hu, H. Zhang, and J.-G. Xu, "Chemical composition, antibacterial activity and mechanism of action of essential oil from seeds of fennel (Foeniculum vulgare Mill.)," Food Control, vol. 35, no. 1, pp. 109-116, 2014.
[29] N. Martins, L. Barros, C. Santos-Buelga, M. Henriques, S. Silva, and I. C. F. R. Ferreira, "Decoction, infusion and hydroalcoholic extract of Origanum vulgare L.: different performances regarding bioactivity and phenolic compounds," Food Chemistry, vol. 158, pp. 73-80, 2014.

[30] T. Mihajilov-Krstev, D. Radnović, D. Kitić et al., "Chemical composition, antimicrobial, antioxidative and anticholinesterase activity of Satureja Montana L. ssp montana essential oil," Central European Journal of Biology, vol. 9, no. 7, pp. 668-677, 2014.

[31] C. Sarikurkcu, M. Sabih Ozer, M. Eskici, B. Tepe, Ş. Can, and E. Mete, "Essential oil composition and antioxidant activity of Thymus longicaulis C. Presl subsp. longicaulis var. longicaulis," Food and Chemical Toxicology, vol. 48, no. 7, pp. 1801-1805, 2010. 

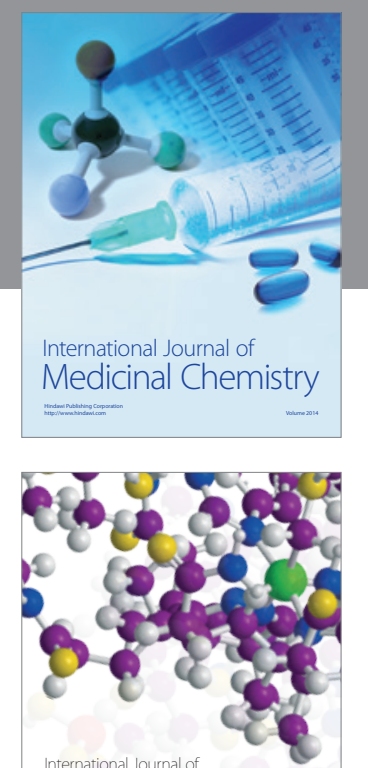

\section{Carbohydrate} Chemistry

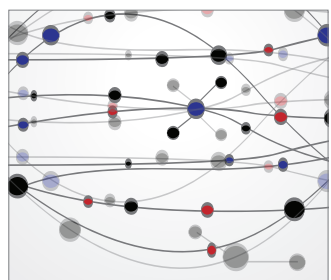

The Scientific World Journal
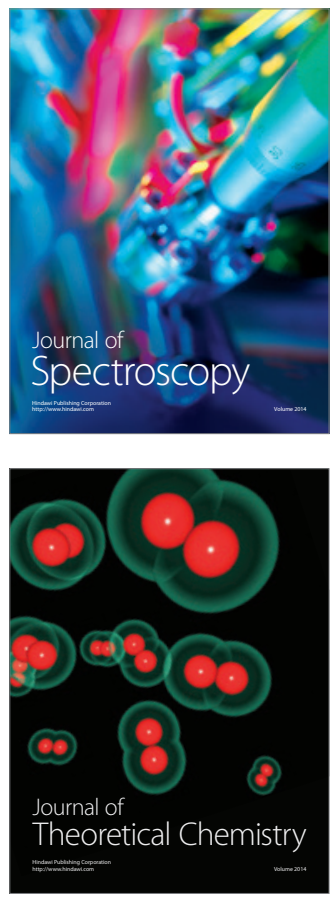
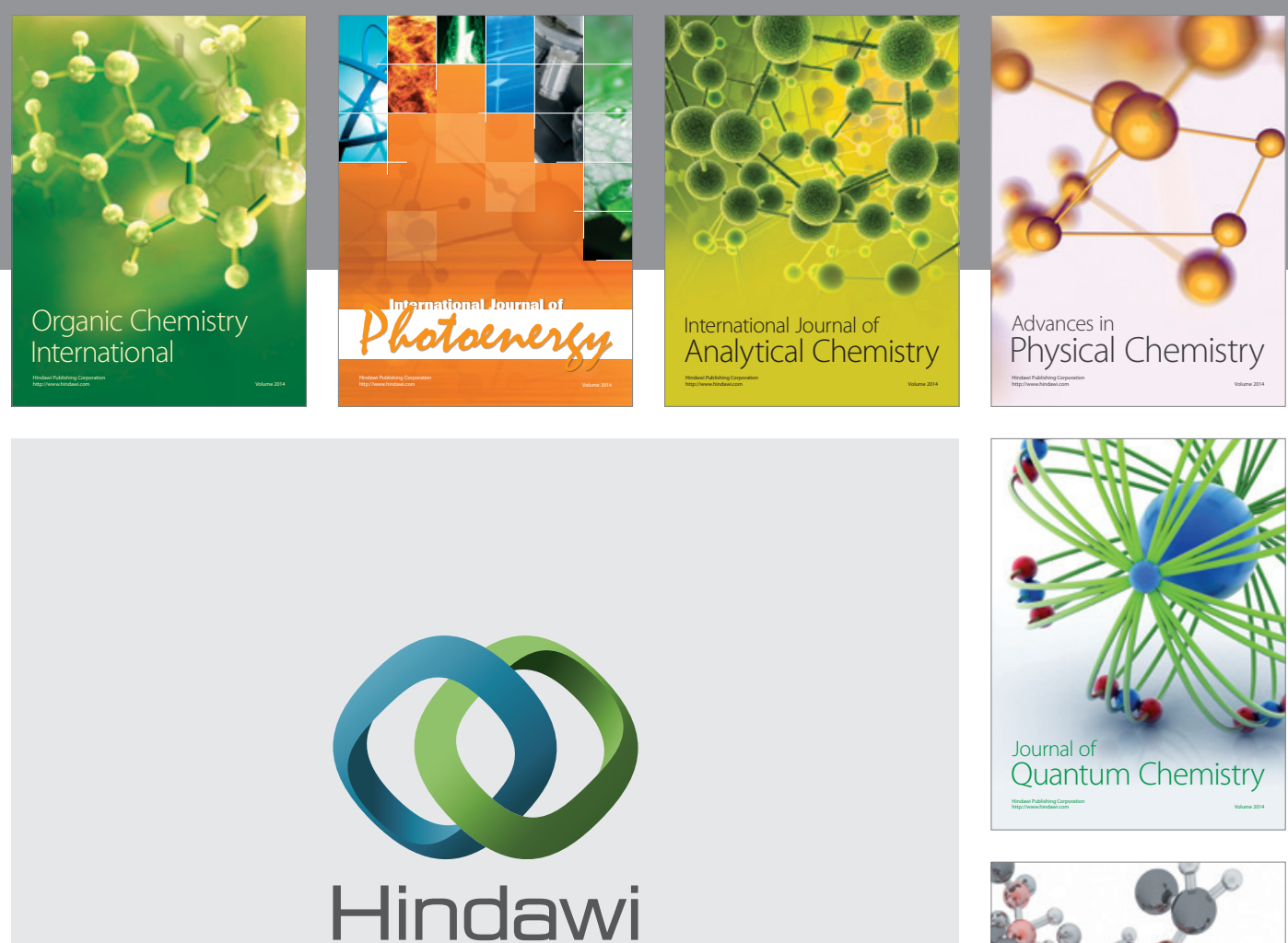

Submit your manuscripts at

http://www.hindawi.com

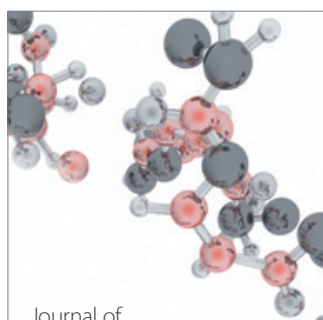

Analytical Methods

in Chemistry

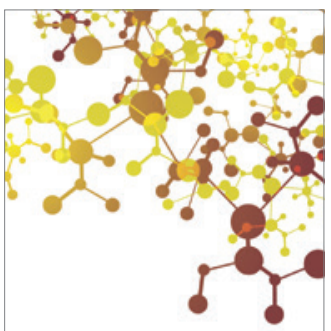

Journal of

Applied Chemistry

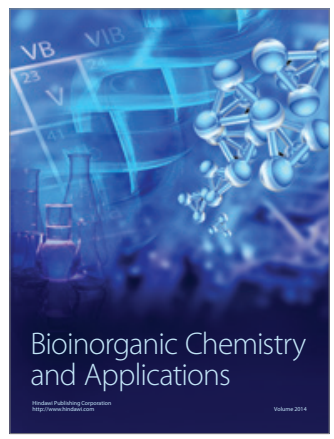

Inorganic Chemistry
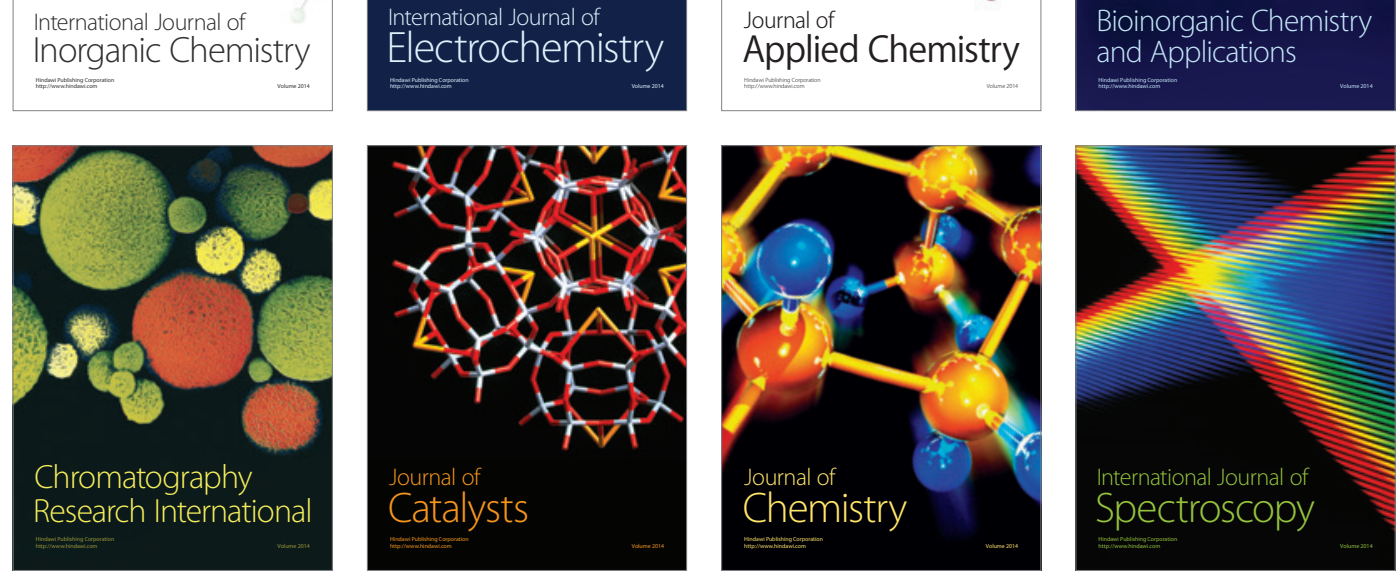